\title{
Big-picture ecology for a small planet
}

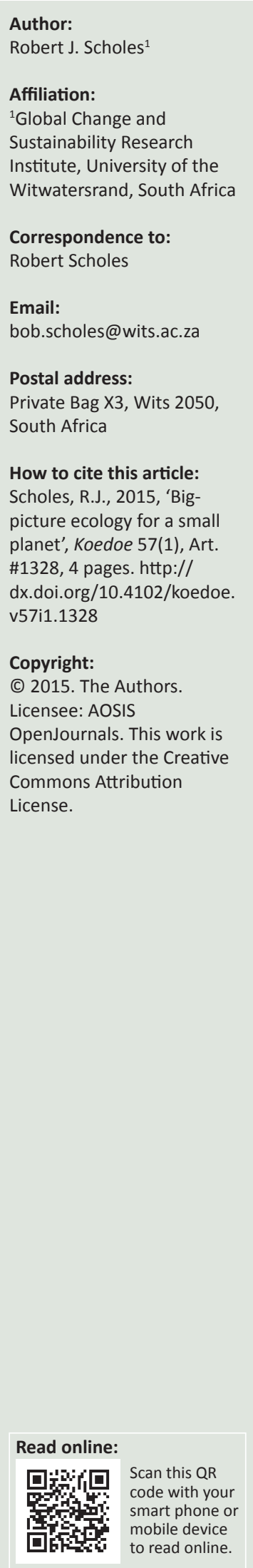

For a number of years, the extensive ecosystems of southern Africa have been a testing ground for ideas and techniques useful for studying and managing large-scale complex systems everywhere, and in particular for tackling issues of global change. The first contribution has been through making consistent, long-term, large-scale observations on climate, vegetation and animal dynamics and disturbances. These have been crucial in developing and testing hypotheses regarding how the earth system works at large space and timescales. The observational techniques have evolved dramatically over time: from notes kept by individuals, to systematic measurement programmes by organisations, to continuous and sophisticated measurements made by automated systems such as satellites and flux towers. The second contribution has been experimental, developing the notion that ecosystems can be the subject of deliberate experimental manipulation. Sometimes this has taken the form of large-scale treatments, such as fire trials or herbivore exclusion plots. More frequently, it has made use of the 'experiment' of the protected area in contrast to its surrounds, or has exploited the information in natural or human-induced gradients. Ecosystem experimentation has required rethinking the fundamentals of experimental design: What is the experimental unit? What is the meaning of a control? What constitutes replication? The third contribution has been theoretical. How does the functioning of warm, dry, species-rich ecosystems differ from the cool, moist, species-poor ecosystem examples that dominate the literature? What are the roles of disturbance and competition is maintaining ecosystem diversity, and top-down versus bottom-up control in maintaining ecosystem structure? The fourth contribution concerns the management of large-scale complex systems in the face of limited knowledge. How can the gap between science and policy be narrowed? What advantages and challenges does participatory co-management offer? How do you implement adaptive management?

\section{The multiple scales of ecosystem change and response}

Ecosystems and social systems are hardly ever static: they change over time, sometimes slowly and sometimes abruptly, and in response to both internal dynamics and external drivers. These changes play out over the surface of the Earth in the form of observable 'patterns', at a range of scales, from that of individual organisms, to patches showing similar attributes, to whole ecosystems, and to the entire biosphere. There is a broad tendency (which is by no means a fixed rule) that slow processes are associated with large spatial scales, and fast processes with small scales (Vance \& Doel 2010). For useful information to be gained, it is necessary to match the scales of observation, in both time and space, with the scales of what is being observed (Englund \& Cooper 2003). Furthermore, it is plausible that interventions in ecosystem processes are more effective if they are matched to the scale of the phenomenon being addressed.

It is therefore an area of concern that the majority of the data collected relating to the state and functioning of the natural and human world is on small scales and over short periods of time (Carpenter 1996; Englund \& Cooper 2003; Levin 1992). This is partly because information at large scales and over long periods was not part of our human experience until relatively recently: we observed locally, and usually for no longer than a human lifespan (and often much less). Written records in archives, travel, telecommunications and space exploration have changed all that. At the same time, human dominance of the world has led to a range of phenomena on regional and global scale - such as climate change, biodiversity loss and ecosystem degradation - which require investigation and intervention on scales far beyond the local and immediate.

There has been a trend in science towards finer and finer resolution, more detail, increased specialisation and narrower disciplines. The scientific approach of reductionism - looking for the causes of things by isolating them and delving down into their underlying elements - has been enormously successful in many fields; however, it has been unhelpful in solving issues which are systemic in nature. System problems emerge from interactions and context, and require a wider 
rather than a narrower view; a view which is often associated with larger scales in space and time. Fortunately, theoretical and technological advances the past few decades have made it increasingly feasible to observe, experiment with and manage systems on the scales at which they actually operate (Schindler 1998).

There is a growing realisation that the phenomena relevant to environmental management operate on a range of scales, rather than on a single scale. Even within a class of issues ('desertification', for instance) several nested scales are often relevant. Thus there is seldom a single 'best' scale for all purposes. The trend is towards multi-scale observation and analysis, and in particular towards trying to understand how phenomena propagate across scales and interact between scales (Scholes et al. 2013).

In classical science, still reflected in science education and attitudes towards data ownership, the researcher made his or her own observations. This is not technically feasible on large scales and over long times; we depend on the accumulation of data from many individuals, the custodianship of institutions and complex and expensive equipment, such as satellites, which are designed and operated by specialists. As a result, the activity of making accurate, repeated observations for use by other scientists is a legitimate aspect of science in its own right, which must be funded and recognised as such.

\section{Large national parks and their surrounds are a useful platform for research}

The act which governs South African protected areas (National Environment Management: Protected Areas Act [Act no. 57 of 2003]) states that the purpose of national parks, amongst other things, is to 'provide spiritual, scientific, educational, recreational and tourism opportunities which are environmentally compatible'. Therefore, conducting scientific activities within parks should not be at the whim of individual park managers: it is part of their mandate, provided it is not in conflict with the broad objective of environmental protection. Nor should such research be selected solely on the basis of its immediate usefulness for park management. The scale, relative absence of human impact, institutional stability and infrastructure of national parks make them uniquely appropriate for certain types of research. Research activities, properly designed and communicated, seldom conflict materially with biodiversity management and tourism activities: generally, visitors are interested in the research and find that it adds value to their experience. Visits by scientists for purposes of research are a significant source of income to the park system.

\section{Datasets of great value}

National parks have accumulated data of value to both themselves and the wider community. Kruger National Park (KNP) is exemplary here, because of its history and size.
In particular, the long-term records pertaining to weather, vegetation composition and state, the populations of mammals and birds and areas affected by fire are near-unique.

The philosophical shift from keeping such data for internal use only to making it openly and freely available which occurred in KNP over the past two decades has resulted in a massive increase in scientific publications relating to the park. It is recognised that collecting and servicing such datasets involves a significant cost to the park system. Experience in many organisations has shown that attempting to recover this cost directly from users is counter-productive: data becomes unaffordable to the users and the expense of invoicing exceeds the income stream. A more sensible approach economically (i.e. considering the needs of society as a whole, rather than the finances of the accounting unit alone) is to treat the cost of data collection as an operating expense to be centrally borne (perhaps supported by specific external grants) and then make the information freely available in order to maximise its use. Use of such data by third parties carries obligations: the data source must be correctly acknowledged; publications arising from its use must be lodged with the data collectors for reporting purposes; and data collected in or on the park must in turn become publically and freely available.

\section{Contributions to global and local knowledge}

There are many domains in which research in large protected areas in South Africa has contributed to global scientific understanding; the following are a few examples amongst many.

\section{The global carbon balance}

Climate change can be thought of as a symptom of disruption to the global carbon metabolism. The emission of fossil fuel-derived carbon dioxide has perturbed a global carbon cycle previously in near-equilibrium, resulting in a rise in atmospheric concentrations and global mean temperature. About half of the emitted carbon dioxide is removed from the atmosphere by marine and terrestrial ecosystems, approximately equally. The uptake by terrestrial ecosystems is globally distributed, and because of their large extent and relatively high productivity, a substantial fraction is probably being stored in savannas such as those covering large parts of Africa. The flux towers operating in the KNP since 2000 help to illuminate this issue. They show that this savanna landscape is alternately a source and sink for carbon, depending on the climate of particular years (Archibald et al. 2009; Kutsch et al. 2008; Williams, Hanan \& Scholes 2009). At the decadal timescale, the two landscapes monitored in the KNP are most likely small carbon sources rather than sinks.

\section{Climate change}

Temperature and rainfall records began at Skukuza in 1912, and have continued daily since then, almost uninterrupted (Kruger, Makamo \& Shongwe 2002). Records at many other 
camps and ranger stations are similarly long and good. There are very few records of this duration in Africa, and they are invaluable in proving the upward trend in global mean (and local) temperature over the past century. The work on greenhouse gas emissions from savanna fires in KNP has been seminal (Swap et al. 2003).The studies relating natural climate variability to plant and animal responses (Archibald \& Scholes 2007; Eckhardt, Wilgen \& Biggs 2000; Wessels et al. 2006) as well as the experimental manipulations of fire (Biggs et al. 2003) and water supply (February et al. 2013) have provided insights into the possible ecological impacts of future climate change.

\section{Biodiversity loss}

National parks exist to protect biodiversity. Especially when large and well managed, they act as reference points for the potential state of biodiversity. Even so, they are not immune from loss of species themselves - or the gain of species through invasions or migration (Chirima, Owen-Smith \& Erasmus 2012; Thrash 1998). Because of the research focus on biodiversity dynamics in national parks, they are often key sources of information for tracking changes and for unscrambling global effects, such as climate change, from local effects, such as changes in habitat and the effects of increases and decreases in key populations (Trollope et al. 1998; Whyte 2004).

\section{Land cover change}

The contrast in land use across national park boundaries is often clearly apparent as a difference in land cover. This sets up an 'experiment' by which the consequences for climate, ecosystem services and biodiversity can be explored. The effect of differing fire regimes within the KNP, and between it and neighbouring lands, has been especially illuminating (Van Wilgen 2009; Van Wilgen et al. 2004).

\section{Implications of big-scale process for management, policy and research priorities}

Much of the day-to-day management in protected areas relates to symptomatic issues, immediate concerns and small scales. This bias affects the information needs as perceived by conservation managers; for example, they routinely prioritise issues relating to population excesses of 'problem species', population viability in rare species, localised degradation and specific instances of conflict with neighbours. The slower, larger-scale processes, which are more likely to threaten the ability to satisfy the mandate of protected area management, and which may be the root cause of many of the crises which dominate management attention, often go unrecorded and unrecognised until too late - land use changes in adjacent areas, climate and atmosphere changes, and economic and political shifts at regional to global scale are some examples. The KNP has been a leader in the practical implementation of adaptive management, the style suggested as most appropriate for ecosystem management in the presence of limited knowledge (Van Wilgen \& Biggs 2011).

\section{Acknowledgements Competing interests}

The author declares that he has no financial or personal relationships which may have inappropriately influenced him in writing this article.

\section{References}

Archibald, S., Kirton, A., Van der Merwe, M., Scholes, R.J., Williams, C.A. \& Hanan N. 2009, 'Drivers of interannual variability in net ecosystem exchange in a semiarid savanna ecosystem, South Africa', Biogeosciences 6, 261-266. http://dx.doi. org/10.5194/bg-6-251-2009

Archibald, S. \& Scholes, R.J., 2007, 'Leaf green-up in a semi-arid African savanna Separating tree and grass responses to environmental cues', Journal of Vegetation Science 18, 583-594.

Biggs, R., Biggs, H.C., Dunne, T.T., Govender, N. \& Potgieter A.L.F., 2003, 'Experimental burn plot trial in the Kruger National Park: History, experimental design and suggestions for data analysis', Koedoe 46(1), 1-15. http://dx.doi.org/10.4102/ koedoe.v46i1.35

Carpenter, S.R., 1996, 'Microcosm experiments have limited relevance for community and ecosystem ecology', Ecology, 77(3), 677-680. http://dx.doi. org/10.2307/2265490

Chirima, G., Owen-Smith, N. \& Erasmus, B., 2012, 'Changing distributions of larger ungulates in the Kruger National Park from ecological aerial survey data', Koedoe 54 Art. \#1009, 11 pages, http://dx.doi.org/10.4102/

Eckhardt, H.C., Wilgen, B.W. \& Biggs, H.C., 2000, 'Trends in woody vegetation

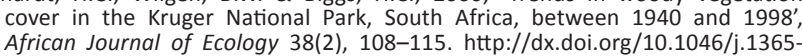
African Journal of

Englund, G. \& Cooper, S.D., 2003, 'Scale effects and extrapolation in ecological experiments', Advances in Ecological Research, 33, 161-213. http://dx.doi. experiments, Advances in Ecological
org/10.1016/S0065-2504(03)33011-9

February, E.C., Higgins, S.I., Bond, W.J. \& Swemmer, L., 2013, 'Influence of competition and rainfall manipulation on the growth responses of savanna trees and grasses', Ecology 94(5), 1155-1164. http://dx.doi.org/10.1890/12-0540.1

Kruger, A.C., Makamo, L.B. \& Shongwe, S., 2002, 'An analysis of Skukuza climate data', Koedoe 45(1), 1-7. http://dx.doi.org/10.4102/koedoe.v45i1.16

Kutsch, W.L., Hanan, N., Scholes, R.J., McHugh, I., Kubheka, W., Eckhardt, H. \& Williams, C., 2008 , 'Response of carbon fluxes to water relations in a savanna ecosystem in South Africa', Biogeosciences 5, 1797-1808. http://dx.doi.org/10.5194/bg-51797-2008

Levin, S.A., 1992, 'The problem of pattern and scale in ecology', Ecology 73, 19431967. http://dx.doi.org/10.2307/1941447

Schindler, D.W., 1998, 'Whole-ecosystem experiments: Replication versus realism The need for ecosystem-scale experiments', Ecosystems 1(4), 323-334. http:// dx.doi.org/10.1007/s100219900026

Scholes, R.J., Reyers, B., Biggs, R., Spierenburg, M.J. \& Duriappah, A., 2013, 'Multi-scale and cross-scale assessments of social-ecological systems and their ecosystem services', Current Opinion in Environmental Sustainability 5, 1-10. http://dx.doi. org/10.1016/j.cosust.2013.01.004

Swap, R.J., Annegarn, H.J., Suttles, J.T., King, M.D., Platnick, S., Privette, J.L. \& Scholes, R.J., 2003, 'Africa burning: A thematic analysis of the Southern African Regional Science Initiative (SAFARI 2000)', Journal of Geophysical Research: Atmospheres 108(D13), 8465. http://dx.doi.org/10.1029/2003JD003747

Thrash, I., 1998, 'Impact of water provision on herbaceous vegetation in Kruge National Park, South Africa', Journal of Arid Environments 38(3), 437-450. http:// dx.doi.org/10.1006/jare.1997.0318

Trollope, W.S.W., Trollope, L.A., Biggs, H.C., Pienaar, D. \& Potgieter, A.L.F., 1998, 'Longterm changes in the woody vegetation of the Kruger National Park, with special reference to the effects of elephants and fire', Koedoe 41(2), 103-112. http:// reference to the effects of elephants
dx.doi.org/10.4102/koedoe.v41i2.255

Vance, T. \& Doel, R., 2010, 'Graphical methods and Cold War scientific practice: The Stommel Diagram's intriguing journey from the physical to the biological environmental sciences', Historical Studies in the Natural Sciences 40(1), 1-47. http://dx.doi.org/10.1525/hsns.2010.40.1.1

Van Wilgen, B.W., 2009, 'The evolution of fire management practices in savanna protected areas in South Africa', South African Journal of Science 105(9-10), 343-349.

Van Wilgen, B.W. \& Biggs, H.C., 2011, 'A critical assessment of adaptive ecosystem management in a large savanna protected area in South Africa', Biological Conservation 144(4), 1179-1187. http://dx.doi.org/10.1016/j. biocon.2010.05.006

Van Wilgen, B.W., Govender, N., Biggs, H.C., Ntsala, D. \& Funda, X.N., 2004, 'Response of savanna fire regimes to changing fire-management policies in a large African national park', Conservation Biology 18(6), 1533-1540. http://dx.doi. org/10.1111/j.1523-1739.2004.00362.x 
Wessels, K.J., Prince, S.D., Zambatis, N., MacFadyen, S., Frost, P.E. \& Van Zyl, D., 2006, 'Relationship between herbaceous biomass and 1-km² Advanced Very High Resolution Radiometer (AVHRR) NDVI in Kruger National Park, South Africa', International Journal of Remote Sensing 27(5), 951-973. http://dx.doi. org/10.1080/01431160500169098
Whyte, I.J., 2004, 'Ecological basis of the new elephant management policy for Kruger National Park and expected outcomes', Pachyderm 36, 99-108.

Williams, C.J, Hanan, N. \& Scholes, R.J., 2009, 'Complexity in water and carbon dioxide fluxes following rain pulses in an African savanna', Oecologia 161, 469-480. http:// dx.doi.org/10.1007/s00442-009-1405-y 